\title{
Protective effect of Celtis tournefortii against copper-induced toxicity in rat liver
}

\author{
Mehmet Ali Temiz ${ }^{1}$, Atilla Temur², Yusuf Akgeyik², Ahmet Uyar ${ }^{3}$ \\ ${ }^{1}$ Karamanoğlu Mehmetbey University, Vocational School of Technical Sciences, \\ Programme of Medicinal and Aromatic Plants, Karaman, Turkey \\ ${ }^{2}$ Van Yuzuncu Yil University, Faculty of Education, Department of Mathematics and Sciences, Van, Turkey \\ ${ }^{3}$ Hatay Mustafa Kemal University, Faculty of Veterinary Medicine, Department of Pathology, Hatay, Turkey
}

Received June 15, 2020

Accepted February 24, 2021

\begin{abstract}
This study aimed to investigate the antioxidant and hepatoprotective effects of Celtis tournefortii fruit extract $(\mathrm{Ct})$ against copper-induced liver damage in rats. Thirty-two Wistar Albino rats were divided into four equal groups $(\mathrm{n}=8)$ : Control, Copper $(\mathrm{Cu})$, Copper $+C$. tournefortii $(\mathrm{Cu}+\mathrm{Ct})$, and $C$. tournefortii $(\mathrm{Ct})$. Superoxide dismutase (SOD), glutathione peroxidase (GPx), and catalase (CAT) activities, glutathione (GSH) concentration, malondialdehyde (MDA), total antioxidant status (TAS) and total oxidant status (TOS) were analysed in the liver tissues. Liver histopathology was also evaluated. Alanine aminotransferase and lactate dehydrogenase significantly decreased in the $\mathrm{Cu}+\mathrm{Ct}$ group compared with the $\mathrm{Cu}$ group. Oxidative stress parameters MDA and TOS significantly increased with copper administration, whereas they decreased with $C$. tournefortii co-treatment compared to $\mathrm{Cu}$ group. GSH concentration and TAS showed significant decreases with copper administration. Celtis tournefortii co-supplementation with copper significantly enhanced antioxidant parameters such as TAS, SOD, and GPx. Celtis tournefortii remarkably attenuated degenerative and necrotic changes caused by the oral exposure of copper in the liver tissue of rats. Celtis tournefortii may provide amelioration of the antioxidant status and moderation of severity of liver damage against copper toxicity. The therapeutic use of C. tournefortii may exhibit protective effects in liver injury treatment.
\end{abstract}

Antioxidant, hepatoprotective, oriental hackberry, phytochemicals, TAS, TOS

Copper $(\mathrm{Cu})$ exposure can occur due to pesticide residue exposure (WHO 2003) in agriculture as well as via drinking water contaminated by environmental pollution or by copper water pipe corrosion (Brewer 2012). Excessive copper intake may also occur via consumption of $\mathrm{Cu}$-rich foods such as liver, seafood, nuts, whole grains, and dried fruits. The tolerable upper intake level is $10 \mathrm{mg}$ /day a value which represents the limit for protection of hepatic injury, a potentially critical side effect of excess copper ingestion (DRI 2001). $\mathrm{Cu}$ is a bioelement and a vital transition metal whose deficiency or excess in humans is associated with pathological situations, especially in liver and brain tissues. However, $\mathrm{Cu}$ metabolism is generally regulated by absorption and biliary excretion mechanisms. $\mathrm{Cu}$ chaperones, $\mathrm{Cu}$ transporters, and $\mathrm{Cu}$-binding proteins/enzymes maintain physiological intracellular $\mathrm{Cu}$ homeostasis ( $\mathrm{Pal} 2014$ ). On the other hand, excess $\mathrm{Cu}$ causes production of free radicals (e.g. reactive oxygen species [ROS]) through Haber-Weiss and Fenton reactions, resulting in tissue damage (Valko et al. 2005). ROS-induced oxidative tissue damage plays an important role in $\mathrm{Cu}$ toxicity. For example, excess $\mathrm{Cu}$ may lead to peroxidative damage to membrane lipids via the reaction of lipid radicals and oxygen to form peroxy radicals, and causes peroxidation in the membranes of hepatocyte lysosomes. Also, $\mathrm{Cu}$ overload also reduces the activity of cytochrome c oxidase and impairs liver mitochondrial respiration (Gaetke et al. 2014).

Phytochemicals are bioactive compounds in plants and they exert a protective effect against various diseases (Zhang et al. 2015). Therefore, their nutraceutical use makes them

Address for correspondence:

Mehmet Ali Temiz

Vocational School of Technical Sciences

Karamanoğlu Mehmetbey University

Phone: +903382262000

Karaman, Turkey 
important in terms of health. The antioxidant and hepatoprotective properties of plants have underscored the importance of plants in discovery of new medications with less side effects for use in hepatic disorder treatment. Celtis tournefortii fruit, commonly known as the "oriental hackberry", is palatable, nutrient-rich, and floury. Celtis tournefortii contains flavonoid and phenolic acids such as gallic acid, vanillic acid, ellagic acid, chlorogenic acid, ferulic acid, caffeic acid, rosmarinic acid, $p$-coumaric acid, myricetin, catechin, rutin, naringin, kaempferol, resveratrol, and quercetin (Keser at al. 2017; Y1ld1r1m et al. 2017). Celtis tournefortii fruits are traditionally consumed for treatment of diarrhoea, dysentery, and peptic ulcers. Some Celtis species are used in epileptic seizures, foot perspiration, and as wound healing remedies. Celtis tournefortii seeds are used by the native population against kidney sand, whereas its leaves are used for stomach pain, menstrual bleeding, sedative purposes, and facilitating digestion (Keser et al. 2017). Although a few in vitro studies (Keser et al. 2017; Y1ld1r1m et al. 2017) have investigated the antioxidant properties of this fruit, the protective effects against hepatotoxicity have not been investigated in vivo. This study exhibits an authentic value due to the acquisition of primary scientific data. Based on this assumption, we aimed to determine the antioxidant and hepatoprotective effects of $C$. tournefortii fruit extract $(\mathrm{Ct})$ against copper-induced toxicity in rats.

\section{Materials and Methods}

\section{Plant material}

Celtis tournefortii fruits were collected from Siirt, Turkey, in August 2016. The plant was taxonomically identified and authenticated by Dr. Metin Armagan, Adnan Menderes University, Aydın. Fruits were dried under shade and powdered.

\section{Celtis tournefortii fruit extraction}

One g powdered Celtis fruit was added to a $100 \mathrm{ml}$ beaker containing $50 \mathrm{ml}$ solvent (water, ethanol $25 \%$, and ethanol $75 \%$, separately) and extracted by stirring for $3 \mathrm{~h}$, at $50{ }^{\circ} \mathrm{C}$ and $750 \mathrm{rpm}$. The extract was then filtrated and centrifuged for $5 \mathrm{~min}$ at $+4{ }^{\circ} \mathrm{C}, 3150 \times \mathrm{g}$ in a falcon tube. The obtained extract was freeze-dried for experimental study. Extraction was performed in duplicate for total phenolic and total flavonoid content analysis.

\section{Determination of total phenolic and total flavonoid content}

The total phenolic content (TPC) in the Ct extract was determined by modified Folin-Ciocalteau reagent method (Singleton and Rossi 1965) using gallic acid as a standard. The TPC was calculated as mg gallic acid equivalent for $100 \mathrm{~g}$ sample (mg GAE/100 $\mathrm{g}$ sample). The total flavonoid content (TFC) was determined by the $\mathrm{AlCI}_{3}$ method (Zhishen et al. 1999) using quercetin as a standard. The TFC was calculated as mg quercetin equivalent for $100 \mathrm{~g}$ sample (mg QE/100 g sample). Analyses were triplicated.

Extract prepared with ethanol $25 \%$ was used in the animal study because of the highest amounts of TPC and TFC in this extract were determined.

\section{Acute toxicity assay (LD50)}

For determining whether $C$. tournefortii fruit extract has acute toxicity, an $\mathrm{LD}_{50}$ study was performed on rats for 7 days. Control and three plant extract groups $(n=6)$ were formed. The rats were fasted for $12 \mathrm{~h}$ before the plant extract was administered. The $\mathrm{Ct}$ was orally administered to rats with a bulbed steel needle at graded single doses $\left(600,1200\right.$, and $2400, \mathrm{mg} \mathrm{kg}^{-1}$ body weight [b.w.]), so a total amount of 24 animals were used. Rats were anaesthetized and sacrificed at the end of the toxicity assay. Then their bloods were collected for liver function test.

Animals and experimental protocol

Experiments on the effects of the Ct were performed on 32 Wistar Albino male rats (150-250 g and 2 months old) obtained from Experimental Application and Research Center, Yuzuncu Yil University (Turkey). Rats were kept at $22^{\circ} \mathrm{C}, 12: 12 \mathrm{~h}$ light/dark cycle in separate stainless cages. They were fed ad libitum standard chow and tap water for 28 days. The experimental groups $(n=8)$ were randomly formed as follows:

Control group received $1 \mathrm{ml}$ saline via gavage daily for 28 days.

Group 2 of rats (CS group) were administered $10 \mathrm{mg} / \mathrm{kg}$ b.w. copper sulphate via intragastric tube twice a week and received $1 \mathrm{ml}$ saline via gavage on other days for 28 days based on the modified method by Temiz et al. (2018).

Group 3 of rats (CS $+\mathrm{Ct}$ group) were administered $10 \mathrm{mg} / \mathrm{kg}$ b.w. copper sulphate via intragastric tube twice a week and received $10 \mathrm{mg} / \mathrm{kg}$ b.w. Ct via gavage daily for 28 days. 
Group 4 of rats (Ct group) received $10 \mathrm{mg} / \mathrm{kg}$ bw $\mathrm{Ct}$ via gavage daily for 28 days.

The present study was approved by Yuzuncu Yil University Animal Researches Local Ethics Committee (no. 27552122-604.01.02-E.7837) and procedures complied with the Guidelines for the Care and Use of Laboratory Animals.

Sample collection

Rats were anaesthetized with ketamine + xylazine at the completion of the experiment. Blood was taken from the heart of each rat by an injector and transferred to serum-separating tubes (SSTs). The tubes were centrifuged at $850 \times \mathrm{g}$ for $10 \mathrm{~min}$ for serum enzymes including aspartate aminotransferase (AST), alanine aminotransferase (ALT), alkaline phosphatase (ALP), and lactate dehydrogenase (LDH) which were analysed in an auto-analyser (Roche Modular PP, Roche Diagnostics, Mannheim, Germany). Serum copper levels were analysed with atomic absorption spectrometer (iCE 3000 Series, Thermo Fisher Scientific, MA, USA) $(\mathrm{y}=0.0857 \mathrm{x}+0.0082$, $\mathrm{R}^{2}=0.9997$ ). Liver tissues were dissected and rinsed by saline. Tissue samples for biochemical evaluation were stored at $-80^{\circ} \mathrm{C}$ until analysis.

\section{Biochemical analyses}

Liver tissues were homogenized in ice-cold phosphate buffered saline (PBS) (pH 7.4) using titanium probe homogenizer (Sonopuls HD 2200, Bandelin, Berlin, Germany) for 3 min and centrifuged at $8,570 \times g$ for 30 $\min$ at $+4{ }^{\circ} \mathrm{C}$. The obtained supernatants of liver tissues of rats were used to analyse glutathione concentration (GSH) (Rizzi et al. 1988) and lipid peroxidation (malondialdehyde, MDA) by measuring thiobarbituric acid reactivity (Slater 1984), glutathione peroxidase (GPx) (Paglia and Valentine 1967), superoxide dismutase (SOD) (McCord and Fridovich 1969), and catalase (CAT) activity (Aebi 1984). Protein quantification was performed by modifying the method by Lowry. The total antioxidant status (TAS) and the total oxidant status (TOS) were performed using commercially available kit (Rel Assay Diagnostic, Turkey) as described by Erel $(2004,2005)$. The TAS method is based on antioxidants in the sample converting the $\mathrm{ABTS}^{+}$radical $\left(2,2^{\prime}\right.$-Azinobis[3-ethylbenzothiazoline-6-sulfonic acid]) into the ABTS form (Erel 2004). The TOS method is based on conversion of ferrous $\left(\mathrm{Fe}^{+2}\right)$ ion complexes of the oxidants present in the sample to the ferric $\left(\mathrm{Fe}^{+3}\right)$ form by oxidation (Erel 2005). Oxidative stress index (OSI) is the ratio of TAS and TOS parameters used to express the status of oxidative stress in tissues. OSI was calculated as per the following formula:

OSI $($ arbitrary unit $)=($ TOS $/$ TAS $) \times 100$

\section{Histopathology}

Liver tissues were taken from the rats and fixed in ice-cold, freshly prepared $10 \%$ formaldehyde for $72 \mathrm{~h}$. Routine paraffin embedding and staining with haematoxylin-eosin were then performed on the liver tissue. The stained sections were evaluated by imaging with a light microscope (80i-DS-Ri2, Nikon, Tokyo, Japan). Histopathological results were evaluated semi-quantitatively according to the degree of the lesion as (-): none; $(+)$ : mild; $(++)$ : moderate; $(+++)$ : severe. $\mathrm{Z}$ ratio test was performed for the importance of the difference between the groups $(\mathrm{n}=8)$ (Minitab 14 statistical software package).

\section{Statistical analysis}

Data were expressed as mean \pm standard deviation. Significant differences between groups were assessed using one-way analysis of variance followed by Tukey's test and Tamhane's T2 (SPSS 18 statistical software package). $P$ values $\leq 0.05$ were accepted as significant.

\section{Results}

The TPC and TFC results of $C$. tournefortii fruit extracts are presented in Fig. 1A-B (Plate IX). The highest amounts of TPC and TFC in the extract were determined in extract prepared with ethanol $25 \%$ (25\% ethanol/75\% water) compared with pure water and ethanol $75 \%$ (ethanol $75 \% / 25 \%$ water). This extract with ethanol $25 \%$ was then chosen for the treatment of experimental animals.

In the lethal dose $\left(\mathrm{LD}_{50}\right)$ study, no $\mathrm{Ct}$ group exhibited mortality. There was no reduction in the physical activity of the rats, no change in their colour of the fur, and no molting. No unusual changes observed in eye coloration, urine colour (bloody urine, dark brown colour etc.), and stool of all treated rats. In the $\mathrm{LD}_{50}$ toxicity study, dose-dependent increases in AST, ALT, LDH, and ALP levels were not significantly seen (Table 1).

Liver serum enzyme levels were used as biochemical markers for early acute hepatic damage (Table 2). Oral exposure of rats to copper significantly increased liver serum enzyme levels compared with control $(P<0.05)$. However, significantly lower values 
Table 1. Serum indicators of $\mathrm{LD}_{50}$ toxicity of rats.

\begin{tabular}{lcccc}
\hline Serum & CG & $600 \mathrm{mg} / \mathrm{kg}$ & $1200 \mathrm{mg} / \mathrm{kg}$ & $2400 \mathrm{mg} / \mathrm{kg}$ \\
\hline AST (U/1) & $120.5 \pm 15.6$ & $126.0 \pm 11.0$ & $127.7 \pm 28.5$ & $144.5 \pm 30.8$ \\
ALT (U/l) & $35.7 \pm 3.7$ & $36.3 \pm 3.1$ & $37.8 \pm 6.4$ & $38.5 \pm 5.2$ \\
LDH (U/1) & $1061 \pm 298$ & $1155 \pm 170$ & $1292 \pm 299$ & $1401 \pm 240$ \\
ALP (U/1) & $263.7 \pm 56$ & $255.3 \pm 19.1$ & $279.3 \pm 32.3$ & $284.2 \pm 32.6$ \\
\hline
\end{tabular}

CG - control group; AST - aspartate aminotransferase; ALT - alanine aminotransferase; LDH - lactate dehydrogenase; ALP - alkaline phosphatase.

Table 2. Serum indicators of rats.

\begin{tabular}{lcccc}
\hline Serum & CG & $\mathrm{Cu}$ & $\mathrm{Cu}+\mathrm{Ct}$ & $\mathrm{Ct}$ \\
\hline AST (U/l) & $119.0 \pm 3.9$ & $153.4 \pm 18.0^{\mathrm{a}}$ & $132.5 \pm 11.5^{\mathrm{a}}$ & $112.9 \pm 13.2^{\mathrm{b}}$ \\
ALT (U/l) & $34.6 \pm 2.4$ & $41.0 \pm 1.5^{\mathrm{a}}$ & $35.9 \pm 4.5^{\mathrm{b}}$ & $34.5 \pm 2.6^{\mathrm{b}}$ \\
LDH (U/1) & $1445 \pm 318$ & $1783.5 \pm 268^{\mathrm{a}}$ & $1589 \pm 145^{\mathrm{b}}$ & $1227 \pm 129^{\mathrm{b}}$ \\
ALP (U/l) & $272.5 \pm 26$ & $295.0 \pm 69.4^{\mathrm{a}}$ & $273.4 \pm 56.3$ & $219.3 \pm 27.1^{\mathrm{b}}$ \\
$\mathrm{Cu}(\mathrm{mg} / \mathrm{l})$ & $1.048 \pm 0.076$ & $1.491 \pm 0.278^{\mathrm{a}}$ & $0.965 \pm 0.188^{\mathrm{b}}$ & $0.475 \pm 0.097^{\mathrm{a}, \mathrm{b}}$ \\
\hline
\end{tabular}

$\mathrm{CG}$ - control group; $\mathrm{Cu}$ - copper group; $\mathrm{Cu}+\mathrm{Ct}$ - copper + Celtis group; $\mathrm{Ct}$ - Celtis group; AST - aspartate aminotransferase; ALT - alanine aminotransferase; LDH - lactate dehydrogenase; ALP - alkaline phosphatase; $\mathrm{Cu}$ - copper.

a - significantly different from the control group $(P<0.05){ }^{\text {b }}$ - different from the Cu group $(P<0.05)$.

of ALT and LDH were noted in the Ct co-treatment with copper when compared to the $\mathrm{Cu}$ group. The amount of serum copper decreased in the $\mathrm{Cu}+\mathrm{Ct}$ group compared to the $\mathrm{Cu}$ group $(P<0.05)$.

The liver MDA content, TOS, and OSI as oxidative stress parameters were significantly increased after $\mathrm{Cu}$ administration to rats regarding the control group, indicating the liver ROS generations and oxidative stress induction. Conversely, $\mathrm{Ct}$ co-supplementation with copper significantly restored these indices (Plate X-XI, Fig. 2A-C). However, TOS increased in the $\mathrm{Cu}+\mathrm{Ct}$ group in comparison with control, despite being significantly lower than in the $\mathrm{Cu}$ group $(P<0.05)$. While liver TAS decreased in the $\mathrm{Cu}$ group, it increased with $\mathrm{Ct}$ treatment (Plate XI, Fig. 2D). The TAS was significantly higher in the Ct group compared to all groups.

Subacute copper exposure to rats showed severe inhibitory response on the liver's antioxidant status (Plate XII-XIII, Fig. 3). Liver GSH content and SOD, GPx, and CAT activities were significantly decreased in $\mathrm{Cu}$-exposed rats than in control group, indicating suppressed liver antioxidant defence against ROS. Ct co-treatment with copper significantly recuperated liver SOD and GPx activities compared to the $\mathrm{Cu}$ group. Treatment with only C. tournefortii showed significant increases of antioxidant enzyme activities and GSH than $\mathrm{Cu}+\mathrm{Ct}$ group (Plate XII-XIII, Fig. 3A-D).

Results of histopathological changes and lesions for both control and treated rats are shown in Table 3. No histopathological findings were observed in microscopic examination of the liver tissue of the rats in the control group or with $\mathrm{Ct}$ alone. Hepatocytes and portal areas had normal appearance, and remark cord around vena centralis was found regularly. The sinuses between the remark cords were normal (Plate XIV, Fig. 4A,D). Conversely, disseminated centrilobular hepatocellular degeneration and vacuolar degeneration were observed in the liver of $\mathrm{Cu}$-treated rats. Mononuclear cell infiltration was detected in portal areas where lymphocytes with inflammatory cells were predominant. Because of dilatation 
in the sinusoid, dissociation was remarkable in the remark cord structure. The cytoplasm of some hepatocytes had eosinophilic, pyknotic, and karyolytic nuclei. Focal coagulation necrosis was detected, especially in periacinar regions, where partial proliferation in Kupffer cells was observed (Plate XIV, Fig. 4B). Mild degenerative changes were observed in the livers of rats treated with $\mathrm{Ct}$ and copper. However, lymphocytic mononuclear cell infiltrations were rarely seen (Plate XIV, Fig. 4C).

Table 3. Histopathological changes in the control, $\mathrm{Cu}, \mathrm{Cu}+\mathrm{Ct}$, and $\mathrm{Ct}$ groups of rats.

\begin{tabular}{|c|c|c|c|c|}
\hline Changes/lesions in liver & Control & $\mathrm{Cu}$ & $\mathrm{Cu}+\mathrm{Ct}$ & $\mathrm{Ct}$ \\
\hline 1. Dilatation of sinusoid & $-/ 8$ & $8 / 8^{\mathrm{a}}$ & $3 / 8$ & $-/ 8^{b}$ \\
\hline slight & $*$ & * & 3 & $*$ \\
\hline moderate & $*$ & 5 & $*$ & $*$ \\
\hline severe & $*$ & 3 & $*$ & $*$ \\
\hline 2. Hepatocellular degeneration & $-/ 8$ & $8 / 8^{a}$ & $4 / 8^{b}$ & $-/ 8^{b}$ \\
\hline slight & $*$ & * & 2 & $*$ \\
\hline moderate & * & 5 & 1 & $*$ \\
\hline severe & $*$ & 3 & 1 & $*$ \\
\hline 3. Coagulation necrosis & $-/ 8$ & $8 / 8^{a}$ & $4 / 8^{b}$ & $-/ 8^{b}$ \\
\hline slight & * & 1 & 1 & $*$ \\
\hline moderate & * & 5 & 3 & $*$ \\
\hline severe & $*$ & 2 & $*$ & $*$ \\
\hline 4. Inflammation cell infiltration & $-/ 8$ & $7 / 8^{a}$ & $3 / 8$ & $-/ 8^{b}$ \\
\hline slight & $*$ & 2 & 2 & $*$ \\
\hline moderate & $*$ & 3 & 1 & $*$ \\
\hline severe & * & 3 & $*$ & $*$ \\
\hline
\end{tabular}

$\mathrm{Cu}$ - copper group; $\mathrm{Cu}+\mathrm{Ct}-$ copper + Celtis group; $\mathrm{Ct}-$ Celtis group.

* - none; ${ }^{\text {a }}$ - significantly different from control $(P<0.05) ;{ }^{\text {b }}$ - significantly different from the $\mathrm{Cu}$ group $(P<0.05)$;

${ }^{\mathrm{c}}$ - significantly different from the $\mathrm{Cu}+\mathrm{Ct}$ group $(P<0.05)$.

\section{Discussion}

Presently, the use of phytochemicals is preferred to synthetic supplements (vitamins, minerals, fibre etc.) due to their beneficial pharmacological effects, as they are considered safer and more reliable (Kioukia-Fougia et al. 2016; Scott et al. 2020). These effects could be attributed to the presence of valuable constituents (Zhang et al. 2015; Keser et al. 2017; Y1ldirim et al. 2017). In this study, antioxidant and hepatoprotective effects of $C$. tournefortii fruit were investigated against hepatic damage caused by $\mathrm{Cu}$-toxicity in rats. This study exhibits an authentic value due to the acquisition of primary scientific data.

As regards to the TPC and TFC results, the $25 \%$ hydroalcoholic solvent revealed considerable amount of polyphenolic compounds in the extract compared to pure water and 75\% ethanol. Y1ld1rim et al. (2017) found similar results for TPC in the methanolic extract. However, TFC was higher in the present study than the results of Y1ldirim et al. (2017). The time, temperature and solvent preference in the extraction process may have affected the amount of compounds in the TFC (Temiz and Temur 2017). In addition, the sampling site, the quality of soil, the season etc. may have probably had an effect.

High-dose $\mathrm{Ct}$ extract did not cause death in the $\mathrm{LD}_{50}$ study, nor did it alter any physical condition and activity on the rats. However, a non-significant dose-dependent increase in serum parameters was detected (Table 1). It has been estimated that oral $\mathrm{LD}_{50}$ value was $>2400 \mathrm{mg} / \mathrm{kg}$ b.w. Ntchapda et al. (2008) stated that the $\mathrm{LD}_{50}$ dose of Celtis durandii 
leaf extract were $14.10 \mathrm{~g} / \mathrm{kg}$ with a mortality rate of $42 \%$. In accordance with the current study, the Celtis durandii leaf extract caused an increase in both ALT and AST serum levels (Ntchapda et al. 2008). Another study conducted with a Celtis iguanaea (Jacq.) Sarg. leaf extract considered $\mathrm{LD}_{50}$ to be higher than $2,000 \mathrm{mg} / \mathrm{kg}$ and lower than $5,000 \mathrm{mg} / \mathrm{kg}$ (Gonçalvez et al. 2015). Therefore, high doses of $C$. tournefortii fruit extract may have low toxicity.

Studies have indicated that various forms of copper such as ion, compound, micro and nanoparticle lead to liver damage and cause increased liver serum enzymes including AST, ALT, and ALP (Lee et al. 2016; Arafa et al. 2017; Khalid et al. 2018; Temiz et al. 2018). Transaminase enzyme levels rise in serum as biomarkers of hepatotoxicity when the liver cell integrity is disrupted and parenchymal cells degenerated. However, Celtis treatment of $\mathrm{Cu}$-induced liver-damaged rats contributed to recovery. There is limited data on Celtis spp. use for liver injury. Reportedly, administration of $100 \mathrm{mg} / \mathrm{kg}$ aqueous ethanolic leaf extract of Celtis integrifolia exhibited significant reduction in serum biochemical indicators such ALT and ALP (Geidam and Adole 2014). Polyphenols may not only act as antioxidants terminating free radical chain reactions but also as effective chelators of redox-active metals (Jomova and Valko 2011). Studies on flavonoids such as quercetin, catechin, and rutin have been conducted for discrimination between its antioxidant versus metal ion chelating properties in the red blood cell haemolysate system in vitro. The results showed that flavonoids maintained their efficiency to chelate redox-active metals (Cherrak et al. 2016). Serum copper levels dramatically reduced with $C$. tournefortii treatment concomitantly with $\mathrm{Cu}$. Celtis contains flavonoids which, like a chelator, may have assisted the reduction of copper concentration in the serum by increasing copper excretion. Flavonoids are capable to form stable metal complexes through their multiple $\mathrm{OH}$ groups and the carbonyl moiety. For instance, quercetin which is characterized by three potential bidentate binding sites ( $\alpha$-hydroxy-carbonyl, $\beta$-hydroxy-carbonyl or catechol), can lead to stable metallic complexes. Previous investigation demonstrated that flavonoids are able to complex $\mathrm{Cu}^{2+}$. The $\mathrm{Cu}$-quercetin complexation was suggested to occur via the 4-keto group of the C-ring with additional involvement of the $3 \mathrm{OH}$ or $5 \mathrm{OH}$ group (Cherrak et al. 2016).

In the current study, MDA as well as TOS and OSI, which are an indicator of oxidant/ antioxidant imbalance, exhibited a significant increase in $\mathrm{Cu}$-administered rats (Fig. 2). Besides, TAS is formed by internal and external antioxidant molecules of the cell which act synergistically. Therefore, measurement of the total antioxidant capacity gives more valuable information than separate measurements. Findings of this study exhibited that $\mathrm{Ct}$ co-treatment with $\mathrm{Cu}$ reduced oxidation and increased the antioxidant status compared to the $\mathrm{Cu}$ group. TAS was significantly higher in the $\mathrm{Ct}$ group in comparison with all groups (Fig. 2D). This result showed better the antioxidant effect of $\mathrm{Ct}$ administered alone. In previous studies, the ethanolic extract of $C$. australis and $C$. occidentalis leaves (E1-Alfy et al. 2011) and the hydromethanolic extract of $C$. australis leaves (Filali-Ansari et al. 2015) significantly reduced in vitro MDA formation. The present findings were consistent with Zanchet et al. (2018) who reported that a C. iguanaea supplement significantly decreased lipid peroxidation in cholesterol-fed rats by increasing SOD activity. Moreover, Arafa et al. (2017) reported that in $\mathrm{Cu}$-induced liver, the elevated hepatic ROS and suppressed total antioxidant capacity improved with quercetin treatment. Celtis tornefortii also contains quercetin and other flavonoids as well as other aforementioned phenolic antioxidants (Keser et al. 2017). The decrease in lipid peroxidation and TOS in the treatment with $\mathrm{Ct}$ may be due to the presence of scavenger compounds. Furthermore, animals co-treated with $\mathrm{Ct}$ showed a significant improvement in the GSH content, activities of SOD and GPx compared with $\mathrm{Cu}$-intoxicated rats (Fig. 3). These improvements in antioxidant enzymes conform to previous studies and can be attributed to antioxidant properties of the Celtis species (Dasari et al. 2013; Fall et al. 2017). 
The present and previous studies have demonstrated that $\mathrm{Cu}$ induces severe histological changes and hepatic damage (Li et al. 2008; Ibrahim et al. 2015). Li et al. (2008) stated that $\mathrm{Cu}$ can induce liver damage through an up-regulation of apoptosis regulator B-cell lymphoma-2 associated protein X (Bax) expression. Conversely, co-treatment with $\mathrm{Ct}$ ameliorated liver injury, showing less degeneration and necrotic changes. Celtis co-treatment with copper may prevent liver injury or lead to the recuperation of damaged liver parenchyma. Phenolic and flavonoid compounds in herbs may have beneficial hepatoprotective effects. Studies indicated that many phytochemicals such as quercetin against $\mathrm{Pb}$ (Liu et al. 2013), gallic acid against $\mathrm{NaF}$ (Nabavi et al. 2013), and rutin against Cd (Mirani et al. 2012) effectively prevented hepatic damage against metal intoxication. Mechanisms underlying the effects of these compounds may be attributed to inhibiting the Fenton-like reaction, inhibiting the formation of highly reactive hydroxyl radicals by acting as a radical scavenger donating hydrogen (Ibrahim et al. 2015). Moreover, phytochemicals can induce the expression of endogenous antioxidants, and prevent ROS-mediated oxidative stress on DNA by exerting their antioxidant and anti-apoptotic effects (Ibrahim et al. 2015). Therefore, these phytochemicals may be responsible for the hepatoprotective effects of the Celtis extract. Polyphenolic compounds may synergistically modulate fibrosis and necrosis in the liver. Herbal medicines are mixtures of various phytochemicals that exert synergistically their full beneficial effect in total extracts (Zhang et al. 2019).

In conclusion, the hepatotoxicity of $\mathrm{Cu}$ was corroborated by the data obtained with increasing oxidative stress markers and hepatic degeneration and necrotic changes. However, it was revealed that $C$. tournefortii may have hepatoprotective effects against $\mathrm{Cu}$-induced liver damage due to mitigated oxidative stress indicators and hepatocellular degeneration as well as on an enhanced antioxidant status. The use of $C$. tournefortii as nutraceutical for the maintenance of oxidant/antioxidant balance for liver damage may be efficacious.

\section{Acknowledgement}

This research was supported by the Van Yuzuncu Yil University Scientific Research Projects Foundation (grant number FYL-2016-5479).

\section{References}

Aebi H 1984: Catalase in vitro. Methods Enzymol 105: 121-126

Arafa AF, Ghanem HZ, Soliman MS, El-Meligy E 2017: Modulation effects of quercetin against copper oxide nanoparticles-induced liver toxicity in rats. Egypt Pharma J 16:78-86

Brewer GJ 2012: Metals in the causation and treatment of Wilson's disease and Alzheimer's disease, and copper lowering therapy in medicine. Inorganica Chim Acta 393: 135-141

Cherrak SA, Mokhtari-Soulimane N, Berroukeche F, Bensenane B, Cherbonnel A, Merzouk H, Elhabiri M 2016 : In vitro antioxidant versus metal ion chelating properties of flavonoids: A structure-activity investigation. PLOS ONE 11:1-21

Dasari R, Sathyavati D, Belide SK, Reddy PJ, Abbulu K 2013: Evaluation of antioxidant activity of two important memory enhancing medicinal plants Celtis timorensis and Vanda spathulata. Asian J Pharm Clin Res 6: $153-155$

DRI (Dietary Reference Intakes) 2001: Dietary reference intakes for vitamin A, vitamin K, arsenic, boron, chromium, copper, iodine, iron, manganese, molybdenum, nickel, silicon, vanadium, and zinc. Institute of Medicine (US) Panel on Micronutrients. Washington (DC), National Academies Press (US)

Erel Ö 2004: A novel automated direct measurement method for total antioxidant capacity using a new generation, more stable ABTS radical cation. Clin Biochem 37: 277-285

Erel Ö 2005: A new automated colorimetric method for measuring total oxidant status. Clin Biochem 38: 1103-1111

El-Alfy TS, El-Gohary HMA, Sokkar NM, Hosny M, Al-Mahdy DA 2011: A new flavonoid c-glycoside from Celtis australis L. and Celtis occidentalis L. leaves and potential antioxidant and cytotoxic activities. Sci Pharm 79: 963-975

Fall AD, Dieng SIM, Diatta-Badji K, Diatta W, Bassene E 2017: Phytochemical screening, phenol content and antioxidant studies of ethanol leaf extract of Celtis toka (Forssk.) Hepper\& J.R.I. Wood. J Pharmacogn Phytochem 6: 488-492 
Filali-Ansari N, El Abbouyi A, El Khyari S 2015: Antioxidant properties of leaves and seeds hydromethanolic extracts from Celtis australis. J Chem Biol Phys Sci B 5: 2834-2843

Gaetke LM, Chow-Johnson HS, Chow CK 2014: Copper: Toxicological relevance and mechanisms. Arch Toxicol 88: $1929-1938$

Geidam MA, Adole OS 2014: Effects of the aqueous ethanolic leaves extract of Celtis integrifolia on liver function of wister strain albino rats. Int J Sci Res Manag 2: 713-718

Gonçalves NZ, Lino Júnior RS, Rodrigues CR, Rodrigues AR, Cunha LC 2015: Acute oral toxicity of Celtis iguanaea (Jacq.) Sargent leaf extract (Ulmaceae) in rats and mice. Rev Bras Plantas Med 17: 1118-1124

Ibrahim MA, Khalaf AA, Galal MK, Ogaly HA, Hassa AHM 2015: Ameliorative influence of green tea extract on copper nanoparticle-induced hepatotoxicity in rats. Nanoscale Res Lett 10: 2-9

Jomova K, Valko M 2011: Advances in metal-induced oxidative stress and human disease. Toxicology 283: 65-87

Keser S, Keser F, Kaygili O, Tekin S, Turkoglu I, Demir E, Turkoglu S, Karatepe M, Sandal S, Kirbag S 2017 : Phytochemical compounds and biological activities of Celtis tournefortii fruits. Anal Chem Let 7: 344-355

Khalid S, Afzal N, Khan JA, Hussain Z, Qureshi AS, Hafeez A, Jamil Y 2018: Antioxidant resveratrol protects against copper oxide nanoparticle toxicity in vivo. Naunyn-Schmiedeberg's Arch Pharmacol 391: 1053-1062

Kioukia-Fougia N, Georgiadis N, Tsarouhas K, Vasilaki F, Fragkiadaki P, Meimeti E, Tsitsimpikou C 2016: Synthetic and natural nutritional supplements: Health "allies" or risks to public health? Recent Pat Inflamm Allergy Drug Discov 10: 72-85

Lee IC, Ko JW, Park SH, Lim JO, Shin IS, Moon C, Kim S, Heo J, Kim J 2016: Comparative toxicity and biodistribution of copper nanoparticles and cupric ions in rats. Int J Nanomedicine 11: 2883-2900

Li YW, Wang XH, Nin Q, Luo XP 2008: Excessive copper induces hepatocyte apoptosis and affects Bax and Bcl-2 expression in rat liver. Chin J Contemp Pediatr 10: 42-46

Liu CM, Zheng GH, Ming QL, Sun JM, Cheng C 2013: Protective effect of quercetin on lead-induced oxidative stress and endoplasmic reticulum stress in rat liver via the IRE1/JNK and PI3K/Akt pathway. Free Radic Res 47: 192-201

McCord JM, Fridovich I 1969: Superoxide dismutase. An enzymic function for erythrocuprein (hemocuprein). J Biol Chem 244: 6049-6055

Mirani N, Ashraf JA, Siddique J, Rub A 2012: Protective effect of rutin against cadmium induced hepatotoxicity in Swiss albino mice. J Pharmacol Toxicol 7: 150-157

Nabavi SF, Nabavi SM, Habtemariam S, Moghaddam AH, Sureda A, Jafari M, Latifi AM 2013: Hepatoprotective effect of gallic acid isolated from Peltiphyllum peltatum against sodium fluoride-induced oxidative stress. Ind Crops Prod 44: 50-55

Ntchapda F, Dimo T, Mbongué G, Atchade AT, Kamtchouing P, Enow G 2008: Acute Toxic Effects of the Aqueous Leaf Extract of Celtis durandii Engler (Ulmaceae) on Mice. West Afr J Pharmacol Drug Res 24: 1-7

Paglia DE, Valentine WN 1967: Studies on the quantitative and qualitative characterization of erythrocyte glutathione peroxidase. J Lab Clin Med 70: 158-169

Pal A 2014: Copper toxicity induced hepatocerebral and neurodegenerative diseases: An urgent need for prognostic biomarkers. NeuroToxicology 40: $97-101$

Rizzi R, Caroli A, Bolla P, Acciaioli A, Pagnacco G 1988: Variability of reduced glutathione levels in massese ewes and its effect on daily milk production. J Dairy Res 55: 345-353

Scott SE, Rozin P, Small DA 2020: Consumers prefer "natural" more for preventatives than for curatives. J Consum Res 47: 454-471

Singleton VL, Rossi JA 1965: Colorimetry of total phenolics with phosphomolybdic-phosphotungustic acid reagents. Am J Enol Viticult 16: 144-158

Slater TF 1984: Overview of methods used for detecting lipid peroxidation. Methods Enzymol 105: 283-305

Temiz MA, Temur A 2017: Effect of solvent variation on polyphenolic profile and total phenolic content of olive leaf extract. YYU J Agr Sci 27: 43-50

Temiz MA, Temur A, Kaval Oguz E 2018: Antioxidant and hepatoprotective effects of vitamin E and melatonin against copper-induced toxicity in rats. Trop J Pharm Res 17: 1025-1031

Valko M, Morris H, Cronin MT 2005: Metals, toxicity and oxidative stress. Curr Med Chem 12: 1161-1208

WHO 2003: Copper in drinking-water. Background document for preparation of WHO guidelines for drinking-water quality. World Health Organization, Geneva

Y1ldırım I, Uğur Y, Kutlu T 2017: Investigation of antioxidant activity and phytochemical compositions of Celtis tournefortii. Free Rad Antiox 7: 160-165

Zanchet B, Gomes DB, Corralo VS et al. 2018: Effects of hydroalcoholic extract of Celtis iguanaea on markers of cardiovascular diseases and glucose metabolism in cholesterol-fed rats. Rev Bras Farmacogn 28: 80-91

Zhang YJ, Gan RY, Li S, Zhou Y, Li AN, Xu DP, Li HB 2015: Antioxidant phytochemicals for the prevention and treatment of chronic diseases. Molecules 20: 21138-21156

Zhang L, Virgous C, Si H 2019: Synergistic anti-inflammatory effects and mechanisms of combined phytochemicals. J Nutr Biochem 69: 19-30

Zhishen J, Mengcheng T, Jianming W 1999: The determination of flavonoid contents in mulberry and their scavenging effects on superoxide radicals. Food Chem 64: 555-559 
Temiz M. A.. et al.: Protective ... pp. 91-98
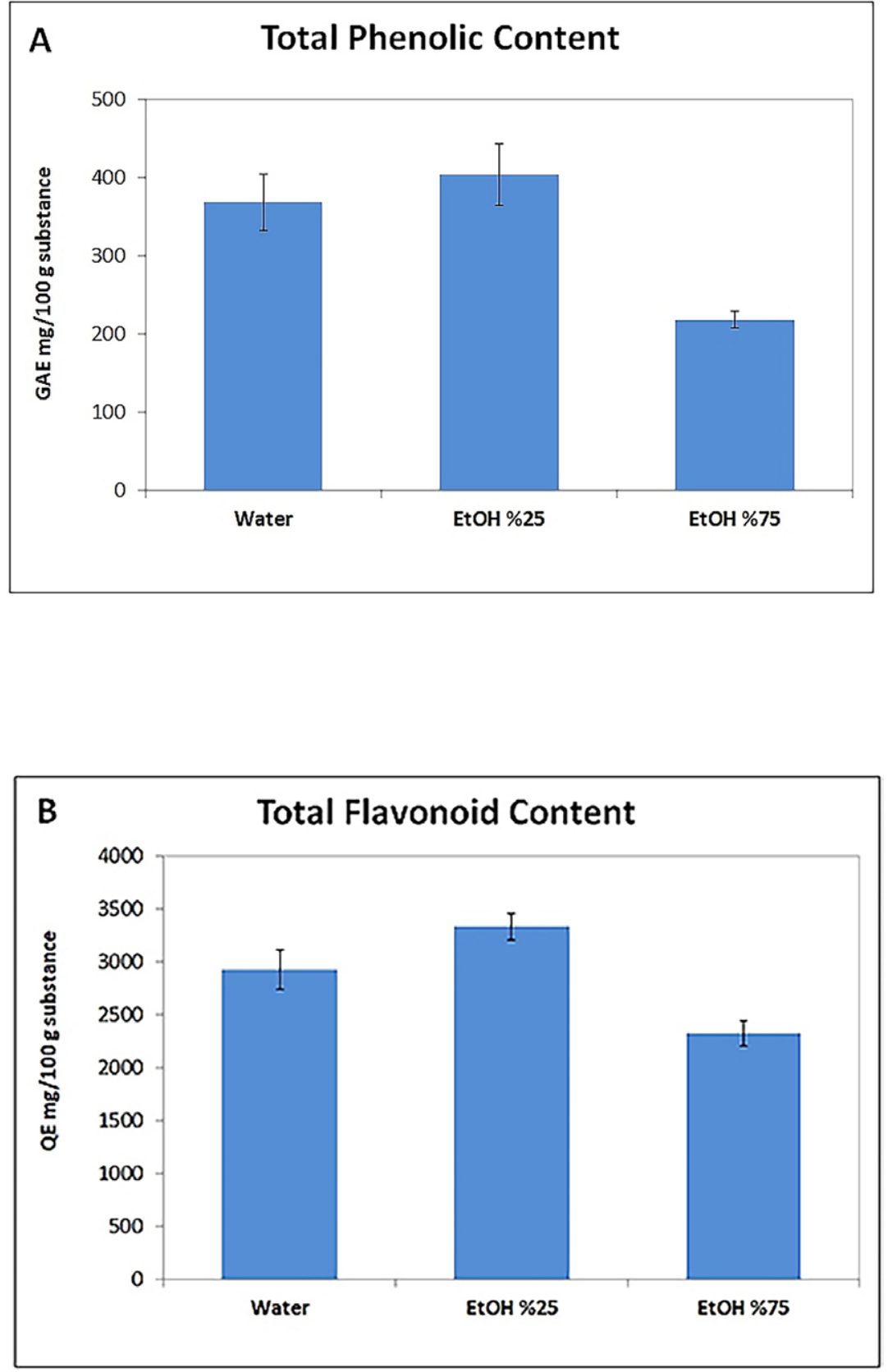

Fig. 1. The total phenolic content (A) and the total flavonoid content (B) in the Celtis tournefortii fruit extract. 
Plate X
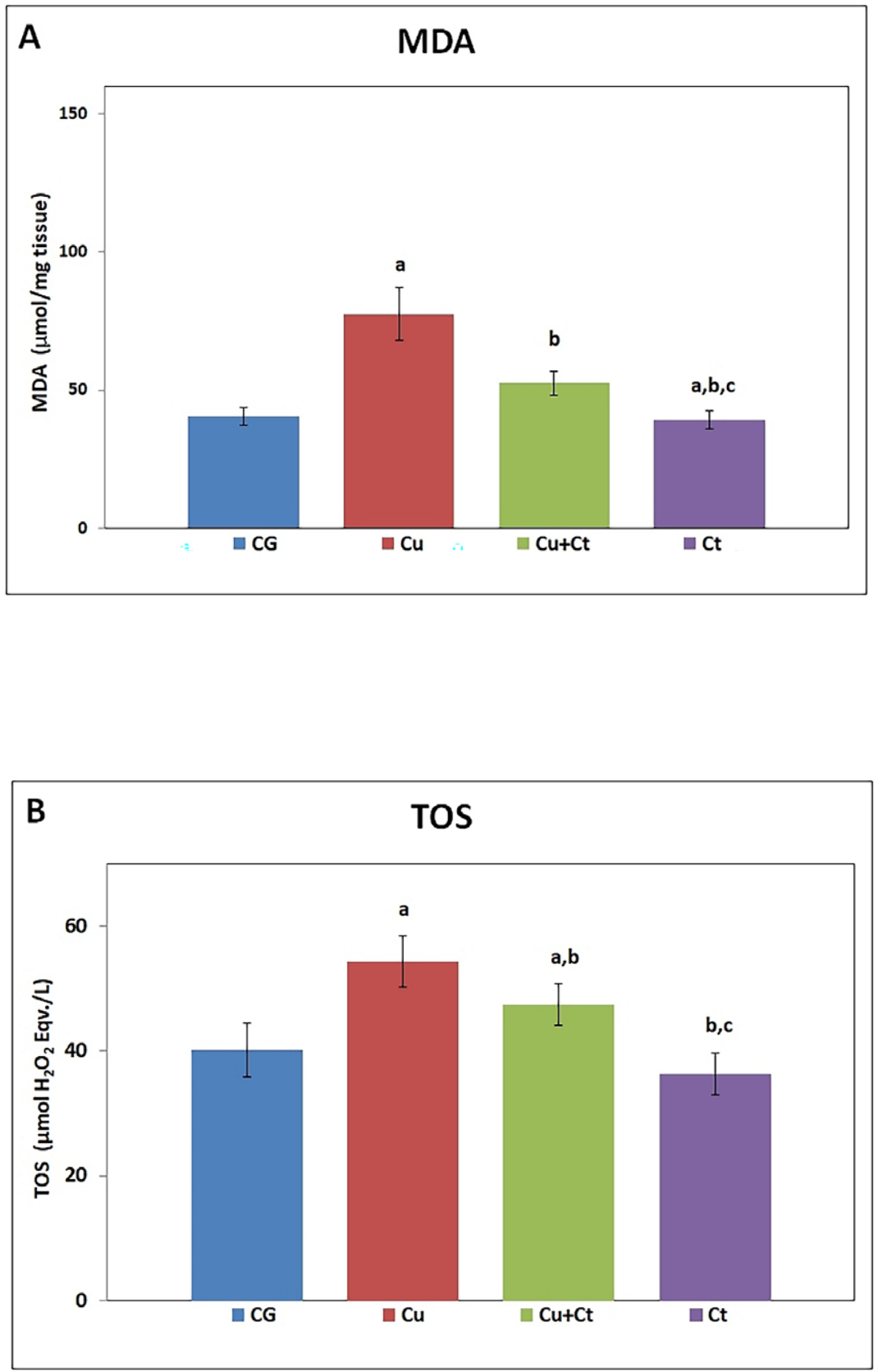

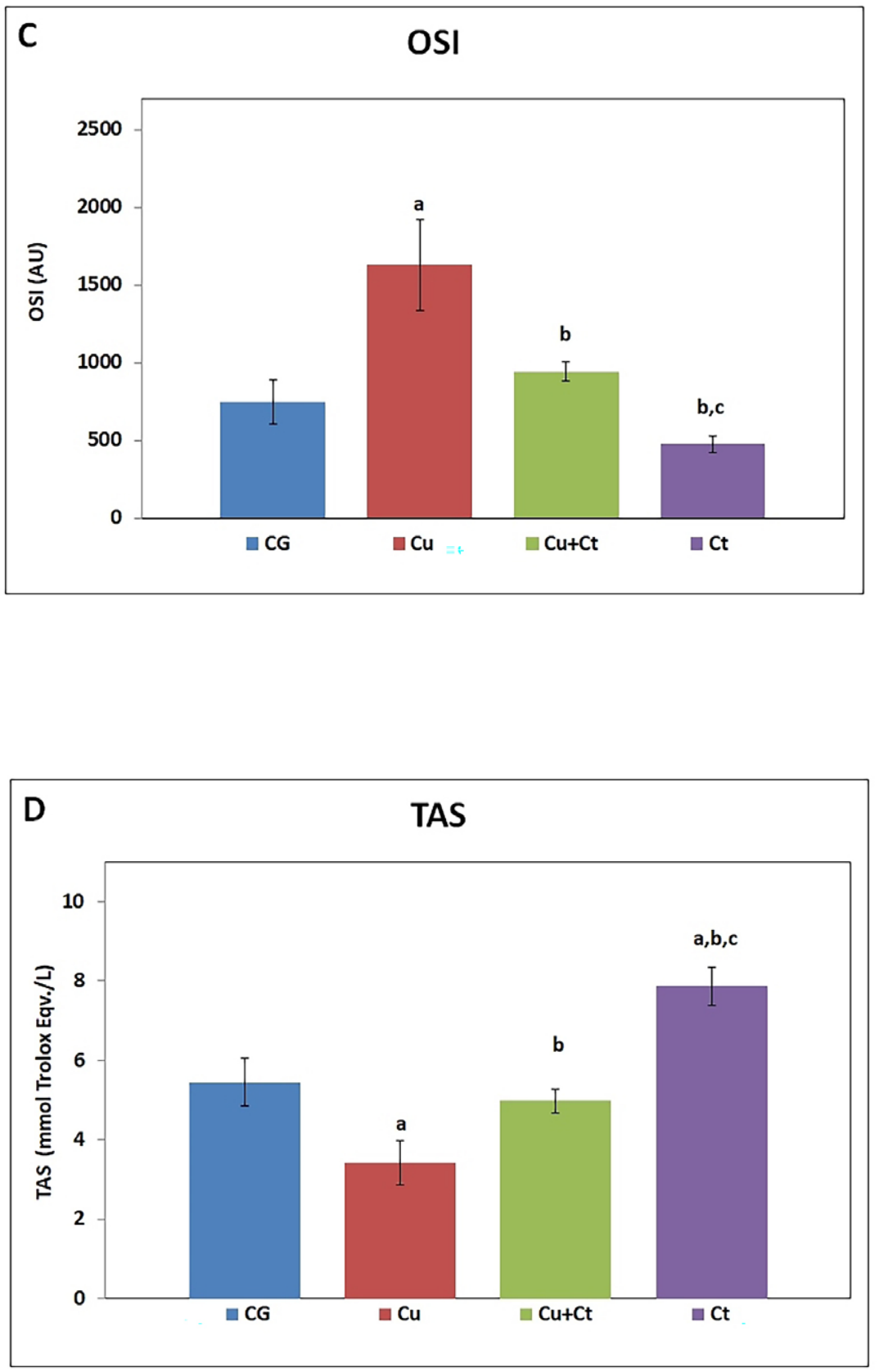

Fig. 2. The MDA content (A), TOS (B), OSI (C) and TAS (D) levels of groups.

MDA: malondialdehyde, TOS: total oxidant status, TAS: total antioxidant status, CG: control group, $\mathrm{Cu}$ : copper group, $\mathrm{Cu}+\mathrm{Ct}$ : copper + Celtis group, $\mathrm{Ct}$ : Celtis group.

a - significantly different from the control group $(P<0.05){ }^{b}$ - significantly different from $\mathrm{Cu}(P<0.05)$;

c - significantly different from the $\mathrm{Cu}+\mathrm{Ct}$ group $(P<0.05)$. 

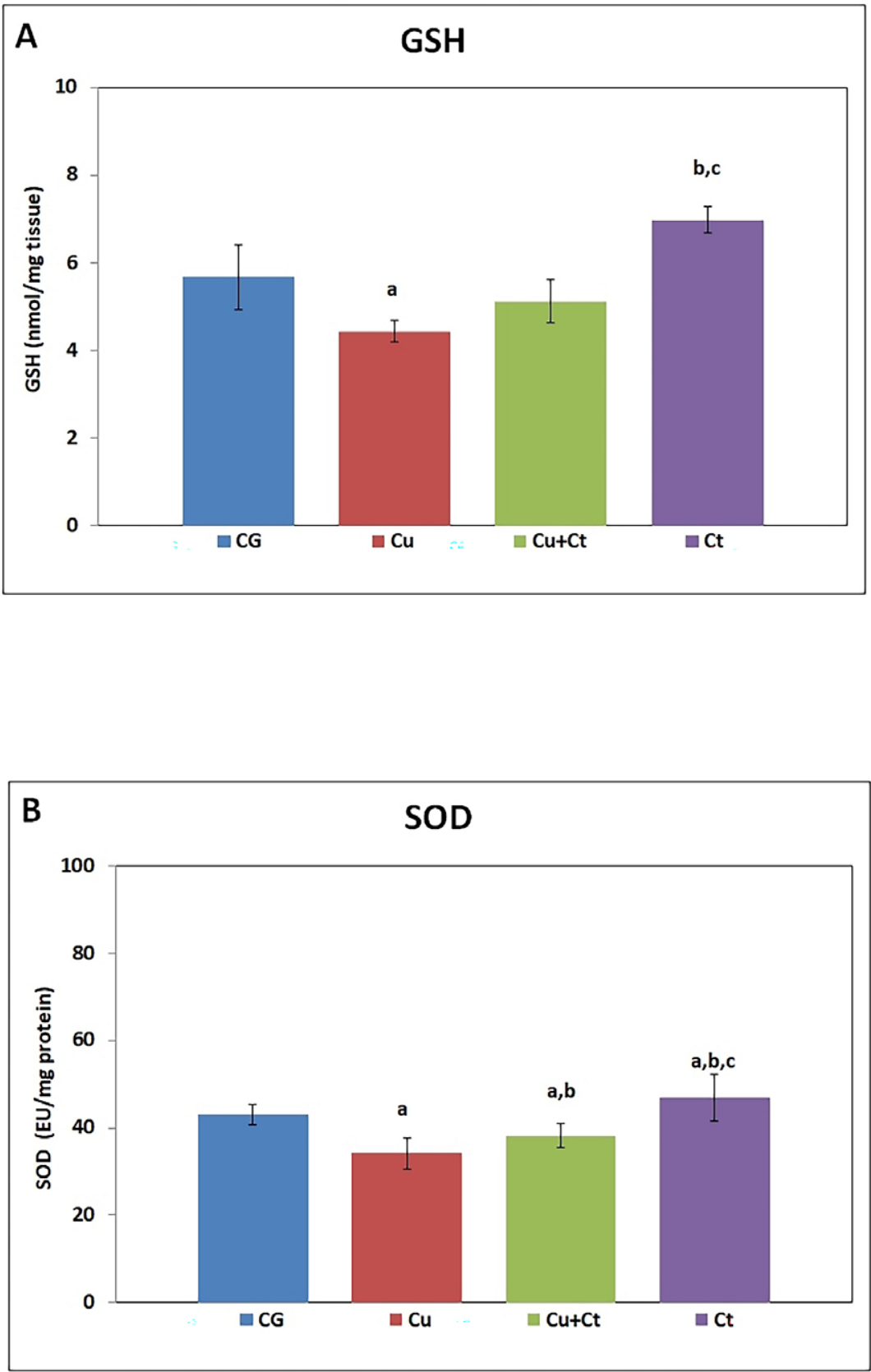

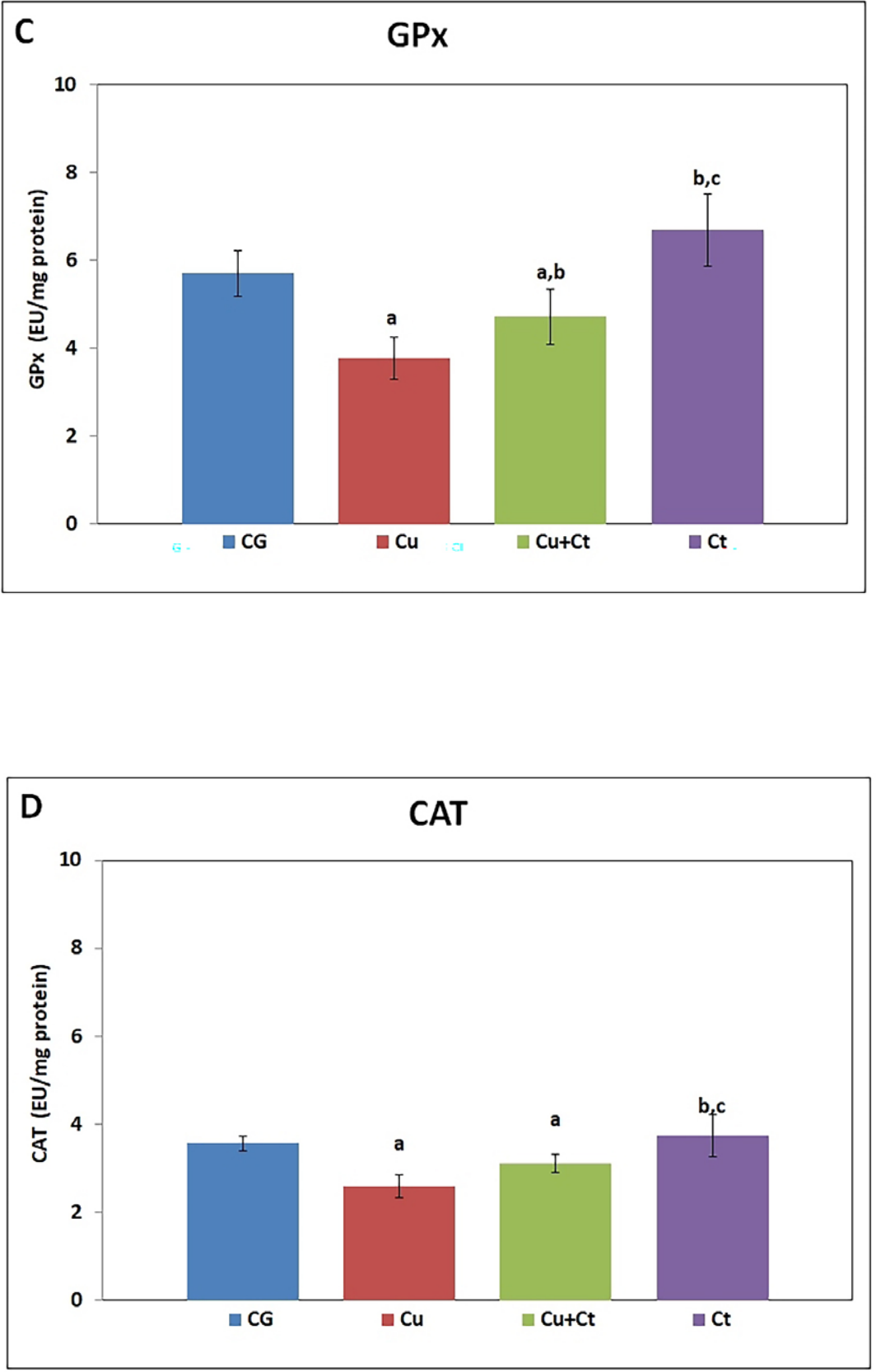

Fig. 3. The GSH content (A) and SOD (B), GPx (C), CAT (D) activities of groups.

GSH: glutathione, SOD: superoxide dismutase, GPx: glutathione peroxidase, CAT: catalase, CG: control group, $\mathrm{Cu}$ : copper group, $\mathrm{Cu}+\mathrm{Ct}$ : copper + Celtis group, $\mathrm{Ct}$ : Celtis group.

a - significantly different from the control group $(P<0.05){ }^{\mathrm{b}}$ - significantly different from the $\mathrm{Cu}$ group $(P<0.05) ;{ }^{c}$ - significantly different from the $\mathrm{Cu}+\mathrm{Ct}$ group $(P<0.05)$. 

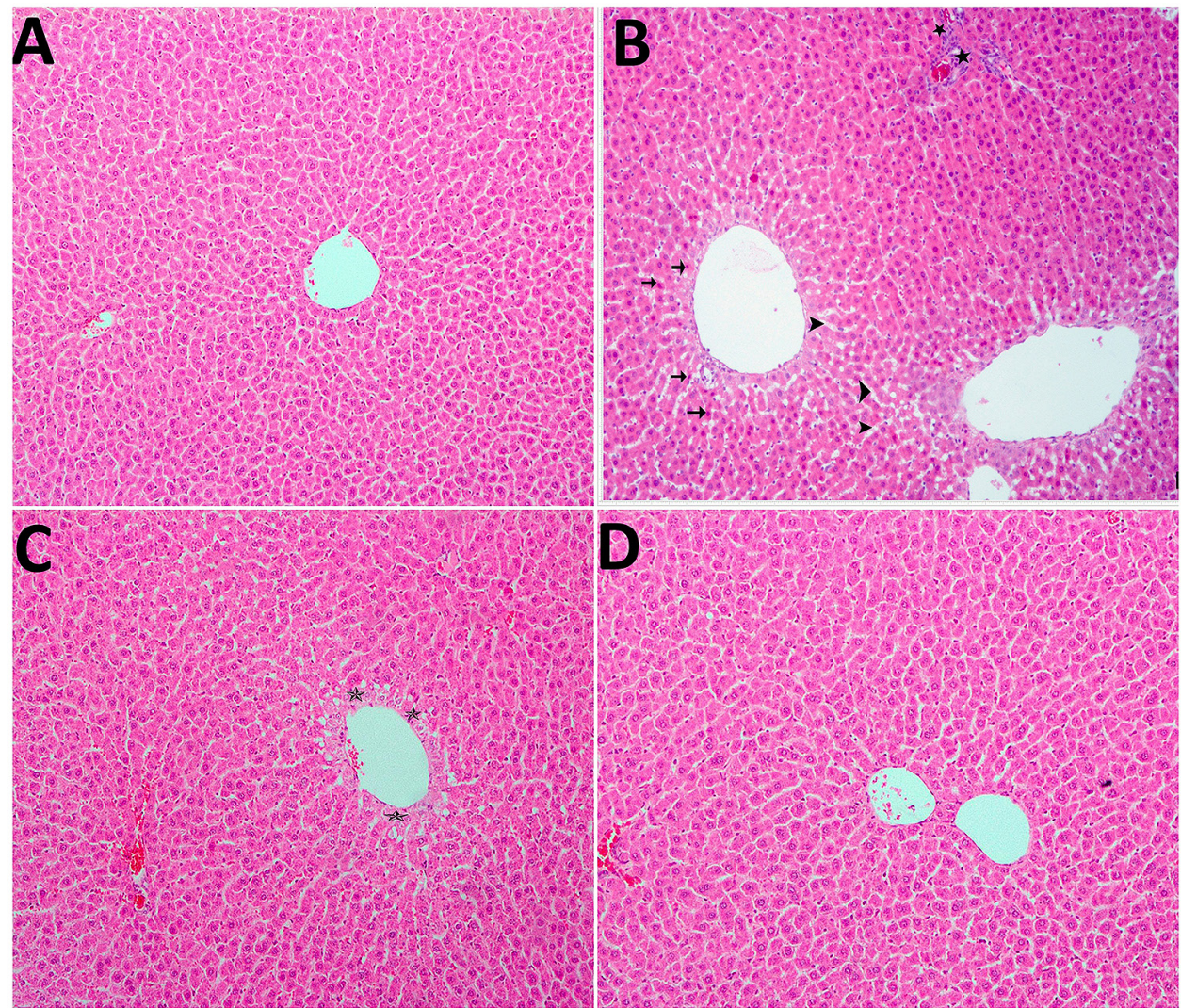

Fig. 4. A: control group, normal histological appearance of the liver; B: Cu group, disseminated centrilobular hepatocellular degeneration and coagulation necrosis (arrows), inflammatory cell infiltration in the portal area (asterisk), dilatation in sinusoid (arrow-heads); $\mathrm{C}: \mathrm{Cu}+\mathrm{Ct}$ group, centrilobular hepatocellular degeneration (asterisk); D: Ct group, normal histological appearance of the liver. $\mathrm{H}+\mathrm{E} \times 10$. Cu: copper group, $\mathrm{Cu}+\mathrm{Ct}$ : copper + Celtis group, Ct: Celtis group. 